\title{
Diagnóstico do perfil do usuário de Drones no Agronegócio Brasileiro
}

Profile diagnosis of users of drones in Brazilian Agribusiness

\author{
Felipe Artioli ${ }^{1 *}$; Tatiane Beloni² \\ 1 Bacharel em Administração - Avenida Príncipe de Gales, 821, Vila Príncipe de Gales, CEP 09060-650 - \\ Santo André (SP), Brasil \\ 2 ESALQ/USP - Doutora em Ciência Animal e Pastagens - Departamento de Zootecnia - CEP 13418-900 \\ - Piracicaba (SP), Brasil
}

\section{Resumo}

O aumento populacional e a crescente demanda por alimentos ao redor do mundo, exigirão que os países aumentem a produção agrícola de suas culturas com a elevação dos índices de produtividade em detrimento a uma diminuição da área geográfica por habitante. $O$ presente trabalho analisou o uso dos drones (do inglês "zangão") ou também conhecido como Veículo Aéreo Não Tripulado [VANT], como uma alternativa tecnológica na Agricultura de Precisão que auxilie o agricultor, os administradores e/ou agrônomos a tomar decisões mais assertivas dentro de sua propriedade. Para tanto, este estudo aplicou questionários em diferentes estados brasileiros à profissionais ligados ao agronegócio, que de maneira geral permitiu constatar que existe uma carência de informações a respeito do uso desta tecnologia, como por exemplo quais são os reais benefícios do uso deste produto, as dificuldades de operacionalizar o equipamento, as regulamentações da Agência Nacional de Aviação Civil [ANAC] e por fim os custos de aquisição do drone. Assim, nota-se que existe um nicho de mercado a ser explorado, devido a uma crescente demanda por este tipo de produto, porém com alguns pontos que devem ser aprimorados para o êxito do uso desta nova tecnologia, como melhor divulgação das empresas que atuam neste segmento, consultoria e cursos aos agricultores e assistência técnica nos principais polos do agronegócio brasileiro.

Palavras-chave: agricultura, mercado, monitoramento agrícola, tecnologia, VANTs

\begin{abstract}
The population growth and the increase demand for food around the world will require the countries to improve agricultural production of their cultures raising the levels of productivity as an option of a decreasing in the geographical area per habitant. This study analyzed the use of drones as a technological alternative in Precision Agriculture to assist farmers to take better assertive decisions within their property. Therefore, this study applied questionnaires in different Brazilian states to professionals related to agribusiness. In general, there is a lack of information regarding the use of this technology such as what are the real benefits of using this product, the difficulties to operate the equipment, the regulation of the National Agency of Aviation [ANAC] and finally the cost to acquire the drone. There is also a niche market to be exploited, due to an increasing demand for this type of product. However, some aspects should be improved for the successful use of this new technology like a better disclosure of companies that operates this segment, consulting and courses for the farmers and technical assistance in Brazilian agribusiness hub.
\end{abstract}

Keywords: agriculture, agricultural monitoring, market, technology, UAVs

\section{Introdução}

O setor agrícola é um dos mais importantes da economia brasileira, pois, embora componha pouco mais de $23,0 \%$ do Produto Interno Bruto [PIB] total da economia

\footnotetext{
1 Autor correspondente <feartioli@uol.com.br> Enviado: 31 maio 2016 Aprovado: 05 jul. 2016
} 
brasileira (MAPA,2014), responsável por quase $\mathrm{R} \$ 100$ bilhões em volume de exportações em conjunto com a pecuária, segundo dados da Secretaria de Relações Internacionais do Ministério da Agricultura, Pecuária e Abastecimento [SRI/Mapa, 2015]. A produção agrícola no Brasil, portanto, uma das principais responsáveis pelos valores da balança comercial do país.

Estimativas mostram que a população brasileira poderá crescer $40 \%$ nos próximos dez anos e a população mundial chegará a nove bilhões de habitantes (FAO, 2015). Fato que, segundo o órgão mundial, exigirá que até 2050 a produção agrícola aumente em $60 \%$ sua produtividade em detrimento a diminuição da área agricultável/habitante.

Dentro deste contexto, o Brasil tem uma grande responsabilidade de se tornar em um curto espaço de tempo (prazo de 10 a 20 anos) um dos principais produtores de alimento do mundo, considerando que poucos países conseguirão suprir esta crescente demanda. Para aumentar a produtividade das lavouras, os produtores rurais terão que buscar o aprimoramento tanto em termos tecnológicos (sistemas inteligentes), como a melhoria de processos e manejo adequado do solo em suas culturas.

No Brasil, a Agricultura de Precisão tem um papel fundamental neste cenário futuro, pois tange na otimização de processos e custos que ajudam o agronegócio a ter mais produtividade gastando menos e evitando desperdícios desnecessários. Existem diversas ferramentas que auxiliam o produtor rural a aumentar a sua eficiência produtiva, como o uso de sensores de solo, o sensoriamento remoto - que possibilita a localização com precisão por meio de fotos de satélites de amplas áreas, e os drones ou Veículo Aéreo Não Tripulado [VANT] recém incorporados no mercado brasileiro, que ajudam no processo de gestão de lavouras, entre outras.

Neste contexto, o uso de drones no Brasil torna-se um aliado na Agricultura de Precisão por ser muito mais preciso, permite detectar e monitorar grandes áreas quase que em tempo real. Por meio de imagens geradas consegue-se identificar onde combater as pragas, ou receber reforços de adubação no solo de forma mais específica, evitando se assim desperdícios, e consequentemente trazendo ao produtor um aumento de produtividade (Zarco, 2012).

Considerando o cenário econômico atual, o aumento da população mundial, a necessidade de incremento da produtividade agropecuária de forma sustentável para atender ao consumo interno e externo, a otimização dos custos da lavoura com o uso das técnicas de Agricultura de Precisão e as novas ferramentas tecnológicas, analisouse o uso dos Drones como uma nova opção na agricultura. 
Para isso, realizou-se uma pesquisa em diferentes estados brasileiros com o objetivo de identificar o perfil do profissional do agronegócio que tende a adquirir este produto, e a partir destes resultados, identificar oportunidades e lacunas desta tecnologia.

\section{Material e Métodos}

No total foram aplicados 71 questionários, com 26 questões, sendo 12 para classificação quanto à faixa etária, perfil socioeconômico e característica do profissional do agronegócio, cinco sobre a Agricultura de Precisão e nove a respeito do uso de drones na Agricultura de Precisão. Os questionários foram disponibilizados por meio da ferramenta do google docs. A divulgação do questionário foi realizada via mídias sociais como linkedin e facebook e e-mails enviado a profissionais do agronegócio. O mesmo formulário também foi aplicado in loco, com auxílio de engenheiros agrônomos e técnicos agrícolas que abordaram fazendeiros ou produtores rurais que não dispõem de recursos tecnológicos para responderem as perguntas.

A pesquisa foi realizada por meio da aplicação de um questionário nos estados de São Paulo [SP], Mato Grosso [MT], Mato Grosso do Sul [MS], Rio Grande de Sul [RS], Paraná [PR], Minas Gerais [MG], Goiás [GO] e outros como Bahia [BA] e Rio de Janeiro [RJ]. A realização da pesquisa compreendeu o período de um mês: de 25 de setembro a 25 de outubro de 2015.

Realizou-se também uma análise descritiva dos dados obtidos e por fim se efetuou a análise SWOT ((SWOT - em inglês strengths (força), weaknesses (fraquezas), opportunities (oportunidades) e threats (ameaças)), para mapear as forças versus fraquezas e quais as oportunidades versus ameaças encontradas neste mercado do uso de drones na Agricultura de Precisão.

\section{Resultados e Discussão}

De 71 entrevistados, $85,9 \%$ eram do gênero masculino e $14,1 \%$ do gênero feminino (Figura 1). O público masculino demonstrou maior interesse e disponibilidade em responder a pesquisa, e também por serem maioria neste segmento de mercado do agronegócio. Por meio dos dados obtidos nesta pesquisa, foi possível traçar de forma mais adequada o perfil do consumidor de drones ou VANTs, assim como as características deste mercado. Para conceituar, a definição de mercado é tido como um composto formado por pessoas ou organizações que possuem desejos ou necessidades e com recursos e disposição para comprar, sendo que um grupo de 
pessoas ou uma organização que não se enquadre em uma dessas características não é classificado como um mercado. Geralmente, os mercados são estratificados pelas seguintes características: geografia, demografia, comportamento e psicografia de acordo com as necessidades e respostas em relação ao produto (Armstrong, 2007).

Por meio da segmentação de mercado com base na análise demográfica como apontado na Figura 1, foi possível fazer um levantamento do perfil do consumidor que atua neste mercado e quais as principais características desse cliente. A maioria das pessoas que participaram da pesquisa está na faixa etária entre 40 a 60 anos (53,6\%), seguindo pelo público de 30 a 40 anos (23,9\%) (Figura 1). Em relação a escolaridade, $59,2 \%$ do público entrevistado possui superior completo e/ou pós-graduação, seguido de $29,6 \%$ que possui o $2^{\circ}$ grau completo e a minoria com $11,3 \%$ que tem até o $1^{\circ}$ grau (Figura 1). No que diz respeito ao perfil socioeconômico, formou-se três faixas salariais: $83,1 \%$ dos consumidores com renda acima de 10 salários, 14,1\% entre 5 e 10 salários e 2,8\% de 1 a 4 salários (Figura 1). Em relação a categoria profissional, 74,6\% da amostragem são fazendeiros, 35,2\% são agrônomos, $21,2 \%$ são técnicos agrícolas ou administradores rurais e $14,1 \%$ enquadram em outra profissão. O levantamento sobre o perfil dos consumidores é muito importante, uma vez que as decisões de compra também são influenciadas por características pessoais que são exclusivas de cada indivíduo, como sexo, idade, perfil socioeconômico, personalidade, autoconceito e estilo de vida (Lamb et al., 2004). 


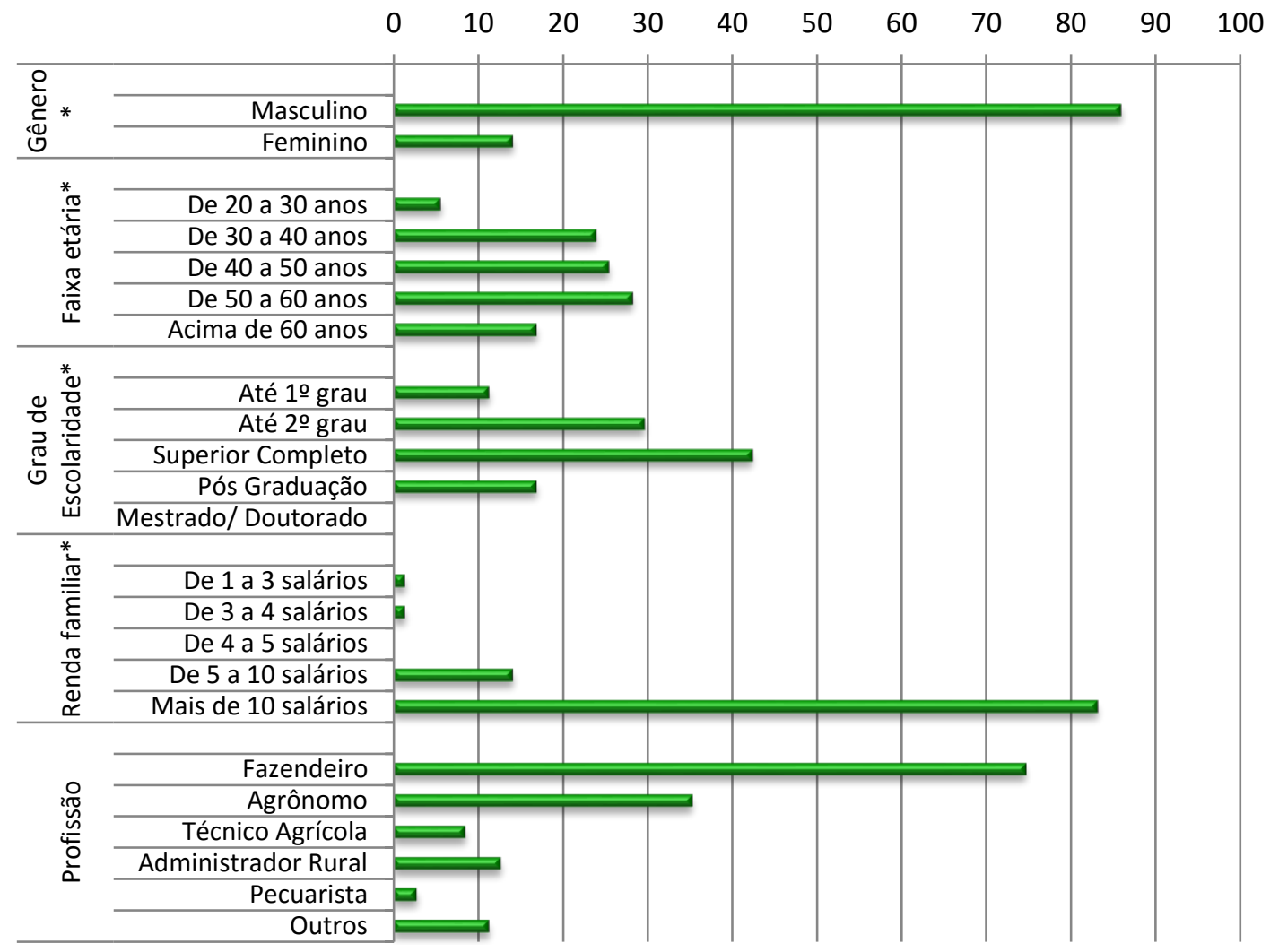

Figura 1. Perfil geral dos entrevistados Fonte: Resultado da Pesquisa

Por meio da análise geográfica foi possível identificar qual o percentual de distribuição dos consumidores pelos estados brasileiros (Figura 2). Notou-se que que existe uma mescla igualitária com pouca diferenciação de concentração de um estado para o outro, mas que ambos foram inseridos nos principais estados do agronegócio brasileiro. Da amostragem, os entrevistados encontram-se nos estados de SP, MT, GO, $P R, R S, M S, M G$ e outros estados como BA e RJ, sendo que nestes concentram-se $49 \%$ da população total do Brasil com aproximadamente 100 milhões de habitantes, e com crescimento médio entre $9,4 \%$ a $16 \%$ de um estado para o outro de acordo com os dados estatísticos brasileiros (IBGE, 2014). Todos os estados possuem alta probabilidade de crescimento populacional e desenvolvimento econômico, o que certamente levará a um maior consumo de alimentos nestes locais e pressionarão os agricultores a aumentarem os índices de produtividades de suas lavouras para suprirem essa demanda. Uma população crescente segundo (Kotler, 2000), significa uma necessidade humana crescente, sendo que o mercado precisará se organizar para atender essa população (Masquietto et al.,2008), levando sempre em conta seu perfil (Kotler, 1996). 

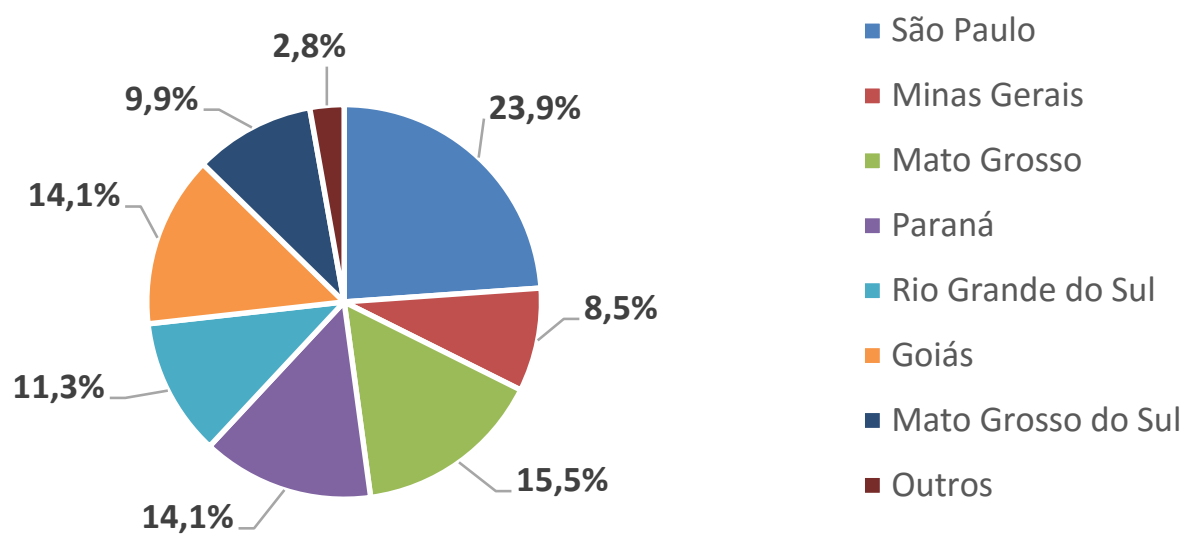

Figura 2. Distribuição geográfica dos entrevistados Fonte: Resultado da Pesquisa

A maioria dos entrevistados possuem imóveis rurais $(85,9 \%)$, distribuídos da seguinte forma de acordo com a classificação de estabelecimentos: $77,9 \%$ são proprietários de fazendas e $11,2 \%$ de sítios. Os demais participantes da pesquisa não possuem imóveis rurais (14,1\%) e 7,4\% da amostragem não se aplicam a esta categoria (Figura 3). Em relação a segmentação de mercado, na categoria de proprietário rural, os imóveis apresentaram diferentes extensões territoriais: $44,3 \%$ dos entrevistados tem fazendas que apresentam de 120 a 240 ha, 27,1\% de 480 ha a 960 ha, 21,4\% de 24 ha a 48 ha, 2,9\% acima de 1.200 ha e 4,3\% que não se aplicam a esta categoria.

O ramo da atividade agropecuária exercida nestas propriedades é, em sua maioria, a cultura de soja com $66,7 \%$, seguido do milho com $50,7 \%$, a cana-de-açúcar com $30,4 \%$, seguido da pecuária com $31,9 \%$ e 7,2\% outras culturas não especificadas. De acordo com a Companhia Nacional de Abastecimento [CONAB] (2015), da produção total de grãos no Brasil, as quatro culturas juntas representam 95\% do volume total produzido no país, sendo que a soja é a cultura com maior percentual de participação com $46 \%$, seguido do milho com $40 \%$, o arroz com $6 \%$ e o trigo com $3 \%$.

Esses estabelecimentos rurais dispõem de maquinários agrícolas, sendo que $73,9 \%$ são tratores, $29 \%$ colheitadeiras, $20,3 \%$ de pulverizadores e $27,5 \%$ que não se aplicam ou possuem outros equipamentos agrícolas (Figura 3). Destes equipamentos utilizados nas propriedades rurais, 40\% não dispõem de tecnologia de navegação por satélite para mapeamento das lavouras, 34,3\% dispõem deste aparelho e $25,7 \%$ dos entrevistados não se aplicam a esta categoria. O mais conhecido sistema é o Global Positioning System [GPS], entretanto não é único. Atualmente, existem mais dois sistemas funcionais GPS e GLONASS e mais dois em desenvolvimento GALILEO e COMPASS (Mundogeo, 2015). Com isto, o aprimoramento tanto em termos 
tecnológicos (sistemas inteligentes), como a melhoria de processos, manejo adequado do solo e defensivos, se faz necessário a incorporação da técnica de Agricultura de Precisão no meio rural em que a variabilidade espacial somente se tornou viável e possível por meio da incorporação de GPS em tempo real (Molin, 2001).

$\begin{array}{lllllllllll}0 & 10 & 20 & 30 & 40 & 50 & 60 & 70 & 80 & 90 & 100\end{array}$

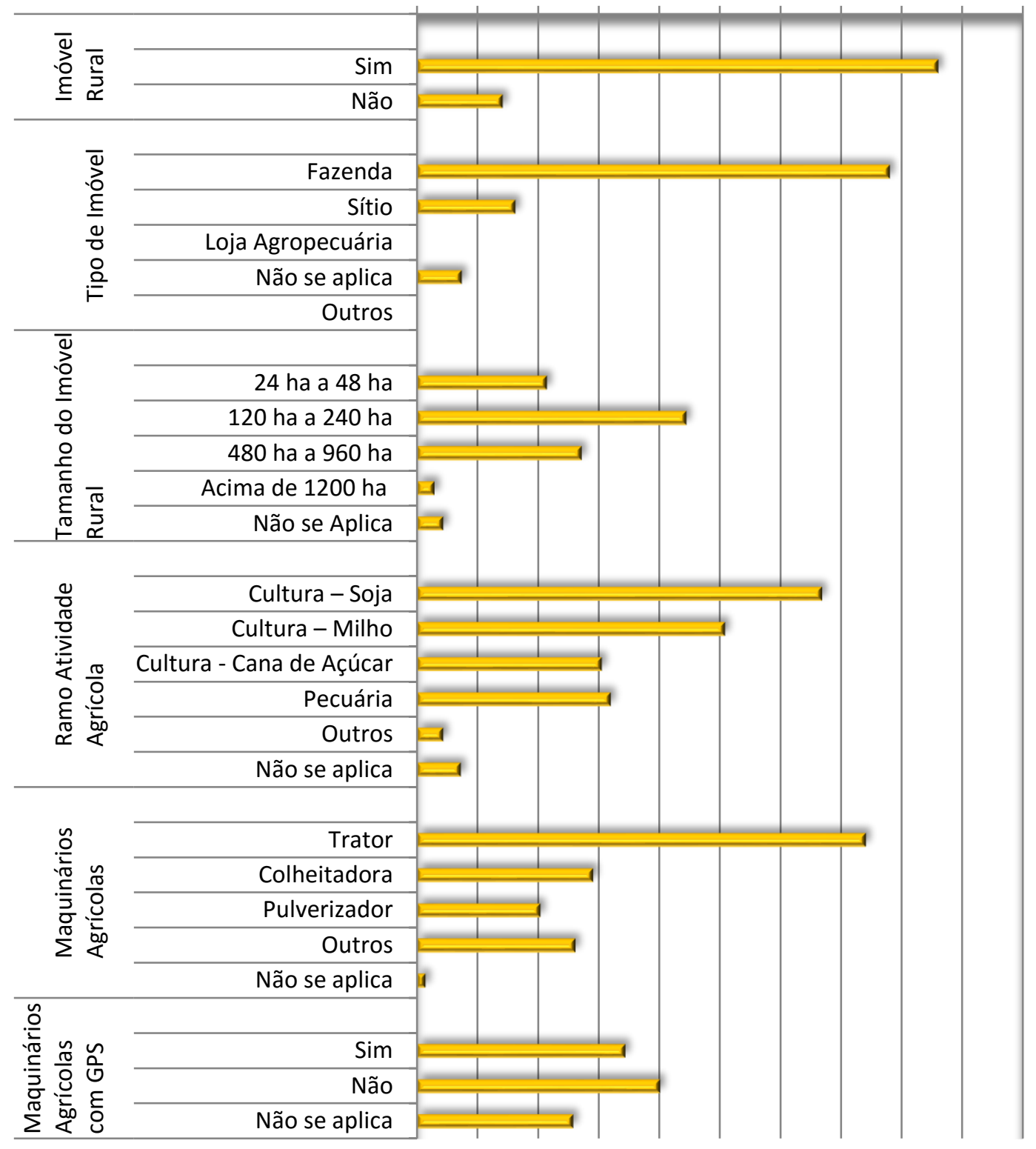

Figura 3. Perfil rural dos entrevistados Fonte: Resultado da Pesquisa

Segundo as estimativas, a população brasileira poderá crescer $40 \%$ nos próximos 10 anos e a população mundial chegará a 9 bilhões de habitantes (FAO, 2015), o que exigirá que até 2050 a produção agrícola aumente em $60 \%$ sua produtividade em 
detrimento a diminuição da área agricultável/habitante. Por meio deste cenário, a Agricultura de Precisão no Brasil tem um papel fundamental no cenário futuro, pois tange na otimização de processos e custos que ajudam o agronegócio a ter mais produtividade gastando menos e evitando desperdícios desnecessários. Entretanto, o conhecimento pela Agricultura de Precisão ainda é pouco explorado nos principais estados brasileiros de acordo com a pesquisa realizada em que $73,2 \%$ dos entrevistados conhecem pouco e $8,5 \%$ desconhecem totalmente, apenas $18,3 \%$ tem conhecimento mais aprofundado sobre os benefícios do uso da Agricultura de Precisão o que torna este mercado bastante atrativo para ser explorado ainda mais (Figura 4).

Com o uso advindo desta tecnologia, se tornou possível georreferenciar todas as atividades dentro das áreas de produção e sua disposição dentro das lavouras que através do monitoramento das áreas se permite ter a variabilidade espacial da produtividade das lavouras. De acordo com os dados coletados no presente estudo, os consumidores que utilizem a Agricultura de Precisão em suas lavouras usam com a seguinte finalidade: $74,3 \%$ dos produtores rurais para o mapeamento dos nutrientes do solo, $57,1 \%$ para o monitoramento de pragas, $50 \%$ para verificar as falhas nas plantações, 28,6\% para detectar as manchas operacionais, 27,1\% para identificar as áreas que tem falta ou excesso de água, 22,9\% para a padronização do espaçamento, $7,1 \%$ para localizar a presença de ervas daninhas e apenas $5,7 \%$ que desconhece total o uso da Agricultura de Precisão nas lavouras (Figura 4). A produtividade das lavouras em forma de mapas especializados direciona a busca da variabilidade específica, ou seja, através de uma análise criteriosa das propriedades físicas e químicas do solo permite identificar as áreas de baixa produtividade assim como as áreas de alta produtividade fazendo a realocação correta dos insumos nas áreas demarcadas evitandos os desequilíbrios (Molin, 2001).

De acordo com os dados coletados, o produtor rural investe, em média, valores altos para uso desta tecnologia em que $44,3 \%$ dos entrevistados gastam de $R \$ 20,00$ a $\mathrm{R} \$ 30,00$ por ha, $22,9 \%$ de $\mathrm{R} \$ 40,00$ a $\mathrm{R} \$ 50,00$ por ha, $12,9 \%$ de $\mathrm{R} \$ 10,00$ a $\mathrm{R} \$ 20,00$ por ha, $1,4 \%$ acima de $\mathrm{R} \$ 100,00$ por ha e o restante não se aplica, desconhece ou não utiliza (Figura 4). Além disso, os gastos com insumos agrícolas por safra, como é o caso dos defensivos, apresentam valores bem altos: $48,6 \%$ dos agricultores gastam acima de $R \$ 100.000,00$ por safra, $17,1 \%$ de $R \$ 40.000,00$ a $R \$ 50.000,00,14,3 \%$ de $R \$$ $20.000,00$ a $R \$ 30.000,00$ e o restante gastam menos ou não se aplica (Figura 4 ). De acordo com o estudo atual, $41,4 \%$ dos produtores rural disseram obter índices de produtividade de 40 sacas ha $^{-1} ; 15,7 \%$ de 30 a 40 sacas ha $^{-1} ; 20 \%$ de 50 a 100 sacas 
ha-1 e; $5,7 \%$ acima de 100 sacas ha $^{-1}$ e os demais não se aplica ou tiveram índices não tão significativos (Figura 4).

Por meio dos dados coletados na pesquisa, este é um tema bastante novo e que merece um aprofundamento maior pelo fato de que $67,1 \%$ dos entrevistados conhecem pouco sobre este novo equipamento, 30\% desconhecem totalmente o que seria este produto e apenas 2,9\% conhece muito bem. Além disso, daqueles que afirmaram terem conhecimento sobre o uso do drone, apenas 18,6\% sabem qual é o seu real benefício, os demais $81,4 \%$, da amostra não possuem nenhuma informação a respeito deste novo produto (Figura 5). De acordo com Medeiros (2007), as pesquisas nessa área no Brasil ainda são muito recentes e os principais trabalhos com VANTs atualmente tem no escopo as aplicações civis, como vigilância policial de áreas urbanas e de fronteira, inspeções de linhas de transmissão de energia e na agricultura seu uso ainda é muito recente.

Os produtores rurais, com base no estudo feito, com o intuito de encontrarem uma redução no custo e uma maior precisão na coleta de informações, estariam dispostos a utilizarem os drones em substituição aos sistemas atuais da Agricultura de Precisão, com as seguintes finalidades: $91,4 \%$ dos entrevistados utilizariam o serviço prestado pelo drone para obter imagens da plantação, 87,1\% para mapeamento dos nutrientes do solo, $71,4 \%$ para monitoramento das pragas, $21,4 \%$ para identificar as regiões que existam deficiência de recurso hídrico e por fim 3\% para realizar a padronização do espaçamento (Figura 5).

A utilização do drone pode ser benéfica para o produtor rural e trazer redução nos custos em comparação as técnicas atuais da Agricultura de Precisão [AP], por ser mais assertivo e com menor tempo para processamento da informação. A pesquisa mapeou que $40 \%$ dos consumidores estariam dispostos a pagarem $R \$ 10,00$ a $R \$ 20,00$ por ha, 38,6\% pagariam de $R \$ 20,00$ a $R \$ 30,0018,6 \%$ de $R \$ 5,00$ a $R \$ 10,00$ e $2,9 \%$ acima de $R \$ 40,00$ a $R \$ 50,00$. Segundo a empresa Bio TI, de Araçatuba (SP), espera oferecer aos produtores rurais o serviço de mapeamento do solo cobrando entre $R \$ 5 \mathrm{e}$ $\mathrm{R} \$ 10$ por hectare, um custo menor ao gasto hoje pelos agricultores que está ao redor de $R \$ 20,00$ a $R \$ 30,00$ por ha se tornando uma técnica bastante atrativa (drone) em substituição aos modelos atuais da AP. 


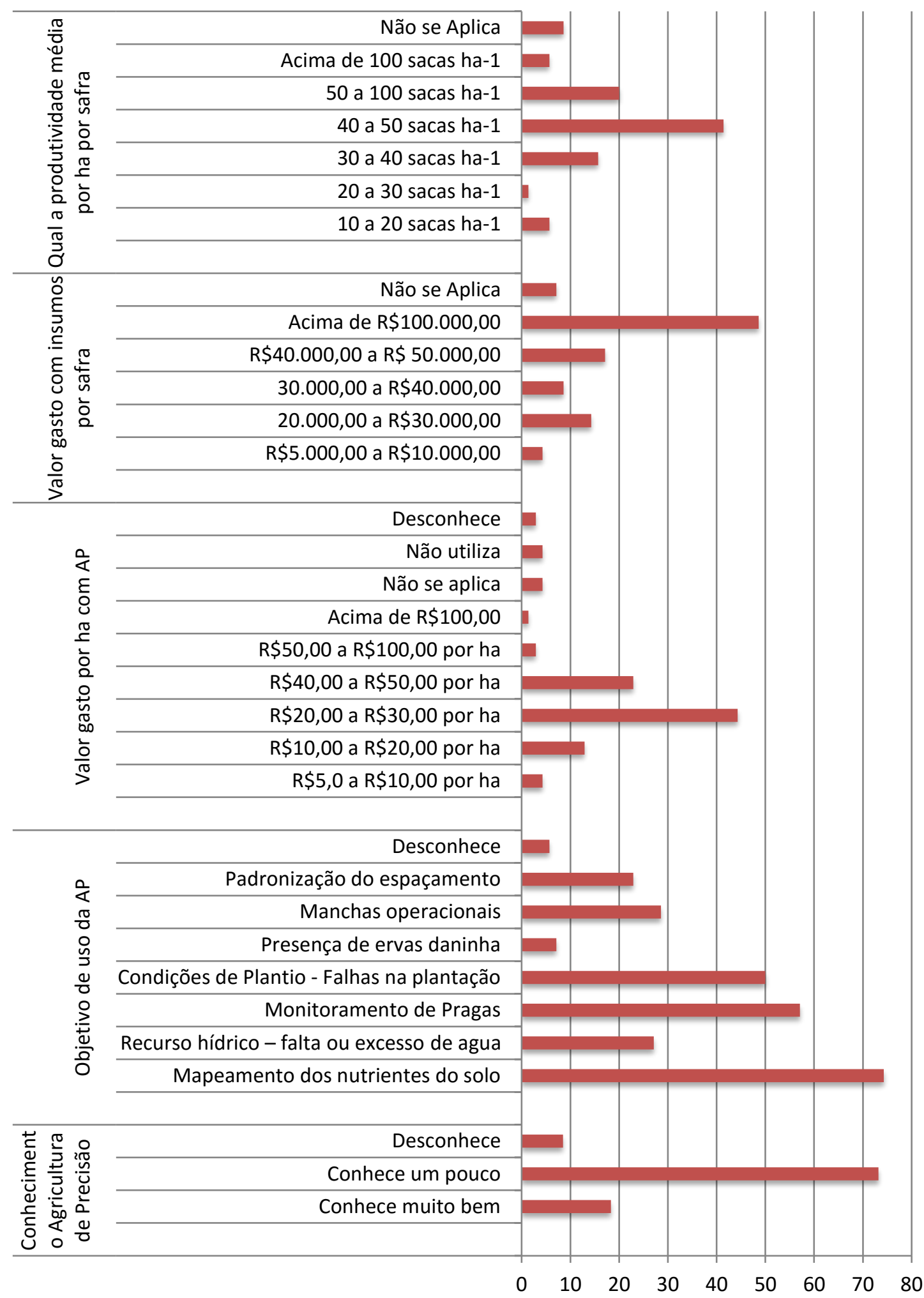

Figura 4. Perfil produtivo e nível utilização e/ou conhecimento da Agricultura de Precisão [AP]

Fonte: Resultado da Pesquisa 
Em relação a produtividade média, espera-se aumentar os índices obtidos em comparação as técnicas atuais com o uso dos drones: $75,7 \%$ dos consumidores esperam que com o uso desta nova tecnologia possam conseguir produzir mais de 50 sacas por ha, $14,3 \%$ de 40 a 50 sacas e $11,2 \%$ de 10 a 40 sacas (Figura 5).

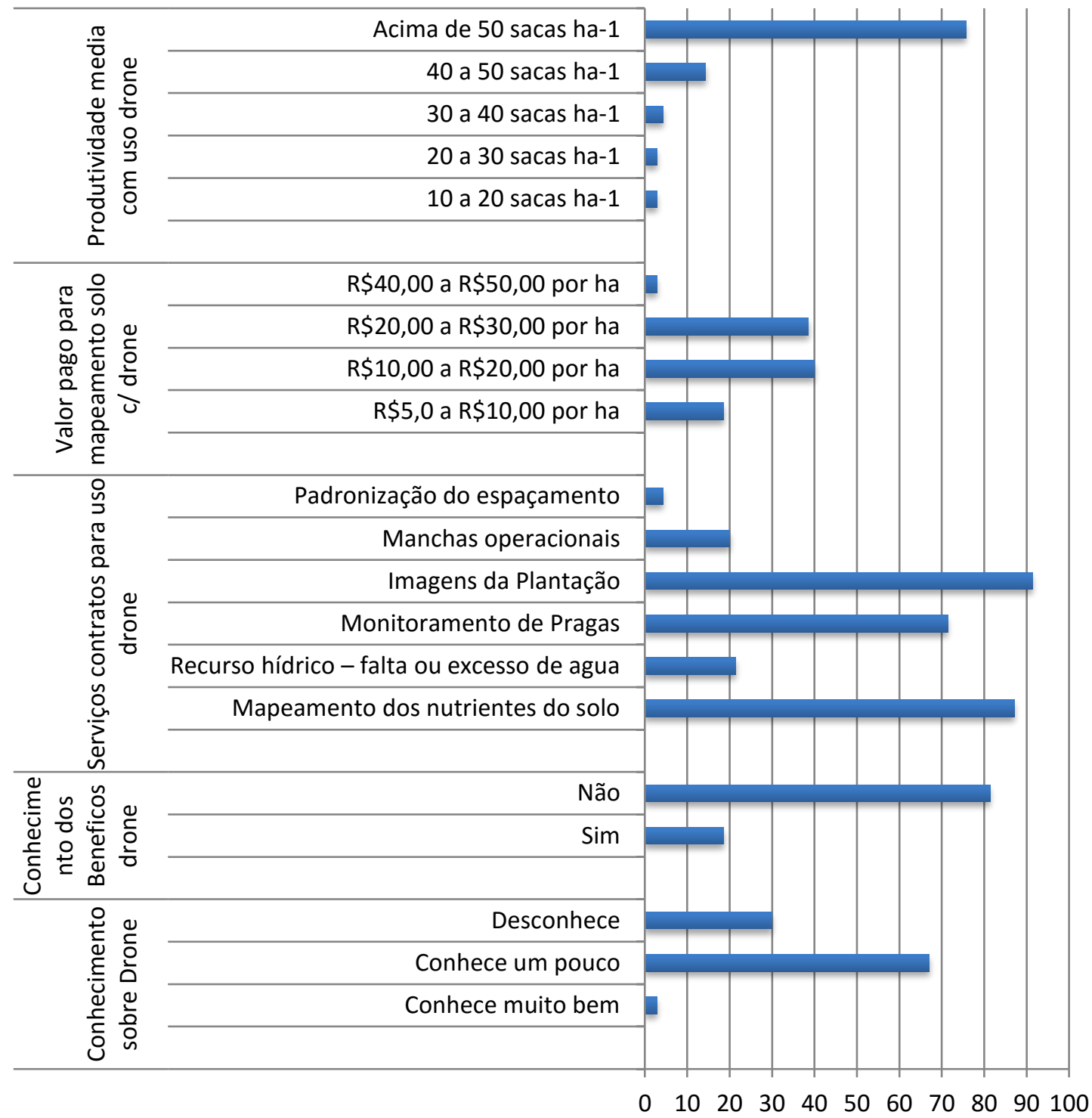

Figura 5. Aceitação e uso de drone ou Veículo aéreo não tripulado [VANTs] pelos consumidores

Fonte: Resultado da Pesquisa

Com base no tempo de aquisição das imagens em uma área geográfica, verificou-se com os entrevistados do presente estudo se haveria interesse em adquirir as informações em menor tempo e com maior precisão, gerados pela captação dos 
drones em substituição aos satélites, e 95,7\% dos consumidores estariam dispostos a contratar o serviço oferecido pelos VANTs e apenas 4,3\% não utilizariam este serviço.

O preço de aquisição do drone ou VANT se diferencia por algumas características, como modelo do equipamento se é asa rotativa ou fixa, altitude de voo, distância percorrida e duração da bateria (autonomia de voo). Estas características é que irão determinar o real valor deste equipamento. De acordo com os dados da pesquisa realizada $55,7 \%$ dos produtores rurais estariam dispostos a pagar entre $R \$ 5.000,00$ e $R \$ 10.000,00,34,3 \%$ entre $R \$ 1.000,00$ e $R \$ 3.000,00,5,7 \%$ de $R \$ 500,00$ a $R \$ 1.000,00$ e $4,3 \%$ entre $R \$ 15.000,00$ a $R \$ 30.000,00$. Segundo a rede Agroservices (BAYER, 2015), as soluções com drones para a agricultura têm um custo que varia entre $\mathrm{R} \$ 400$ (apenas o drone, modelo mais simples disponível no mercado) e $\mathrm{R} \$ 250$ mil (com câmeras e softwares), a depender da complexidade do aparelho e suas finalidades.

De acordo com os resultados obtidos, os produtores rurais em sua maioria estariam dispostos a contratar os serviços dos drones ou VANTs com a finalidade de aumentarem a produtividade de suas lavouras (80\%), 78,6\% para reduzirem o custo de insumos (defensivos agrícolas), 54,3\% para identificar os danos causados por pragas, $50 \%$ para mapear os nutrientes faltantes no solo e assim, providenciarem a correta suplementação, $20 \%$ para terem melhor o controle das pragas, $11,4 \%$ para utilização da águas nas áreas deficitárias mediante aos sistemas de irrigação e por fim 10\% usaria para a padronização dos espaçamentos (Figura 6).

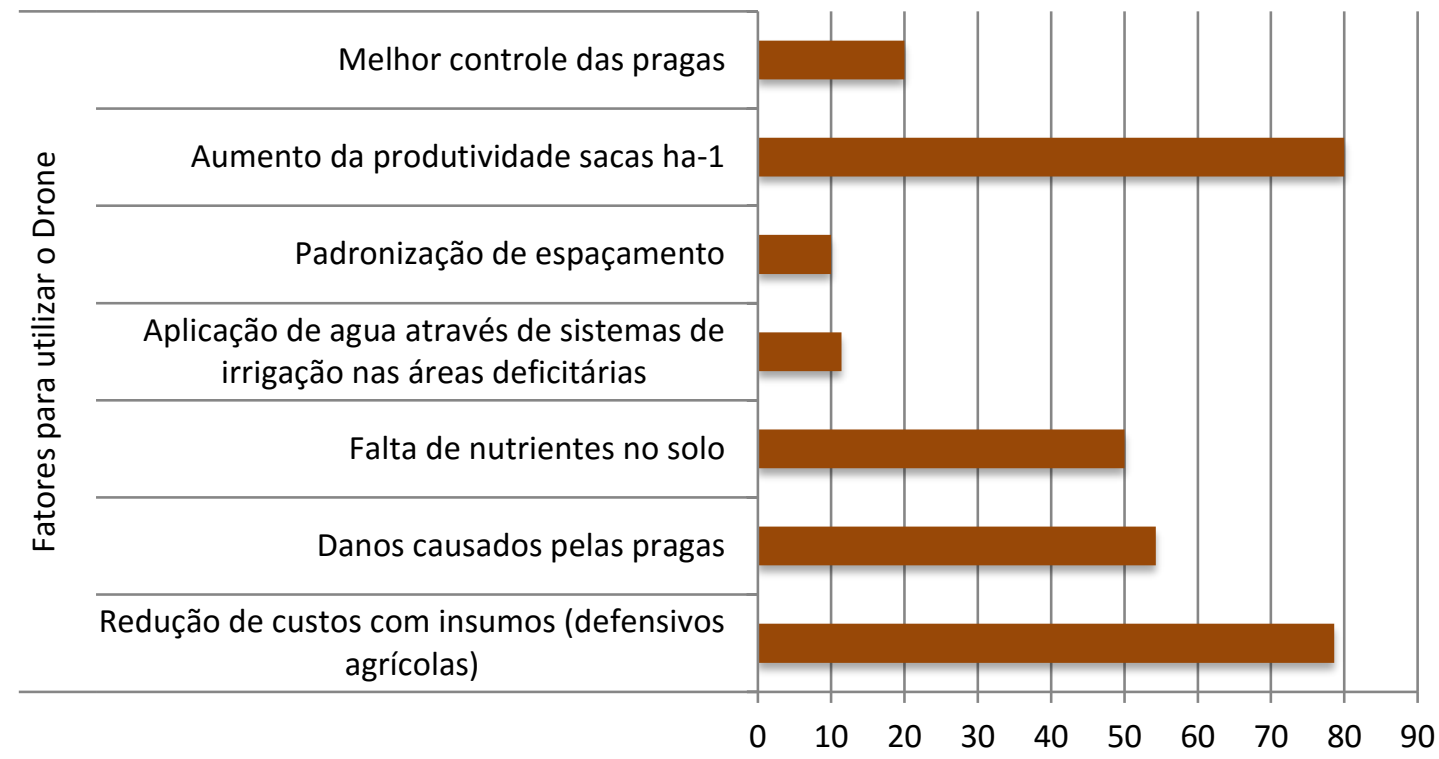

Figura 6. Fatores que levariam profissionais do agronegócio a utilizarem o drone Fonte: Resultado da Pesquisa 
Por meio dos dados obtidos na pesquisa, 71,4\% dos entrevistados acreditam que a maior barreira na adoção desta nova tecnologia é o custo do equipamento e a falta de informações a respeito de suas vantagens e desvantagens, 57,1\% por terem dificuldades de operacionalizar o equipamento, $40 \%$ por falta de regulamentações do governo brasileiro e ANAC e por fim $20 \%$ por falta de peças de reposição (Figura 7 ).

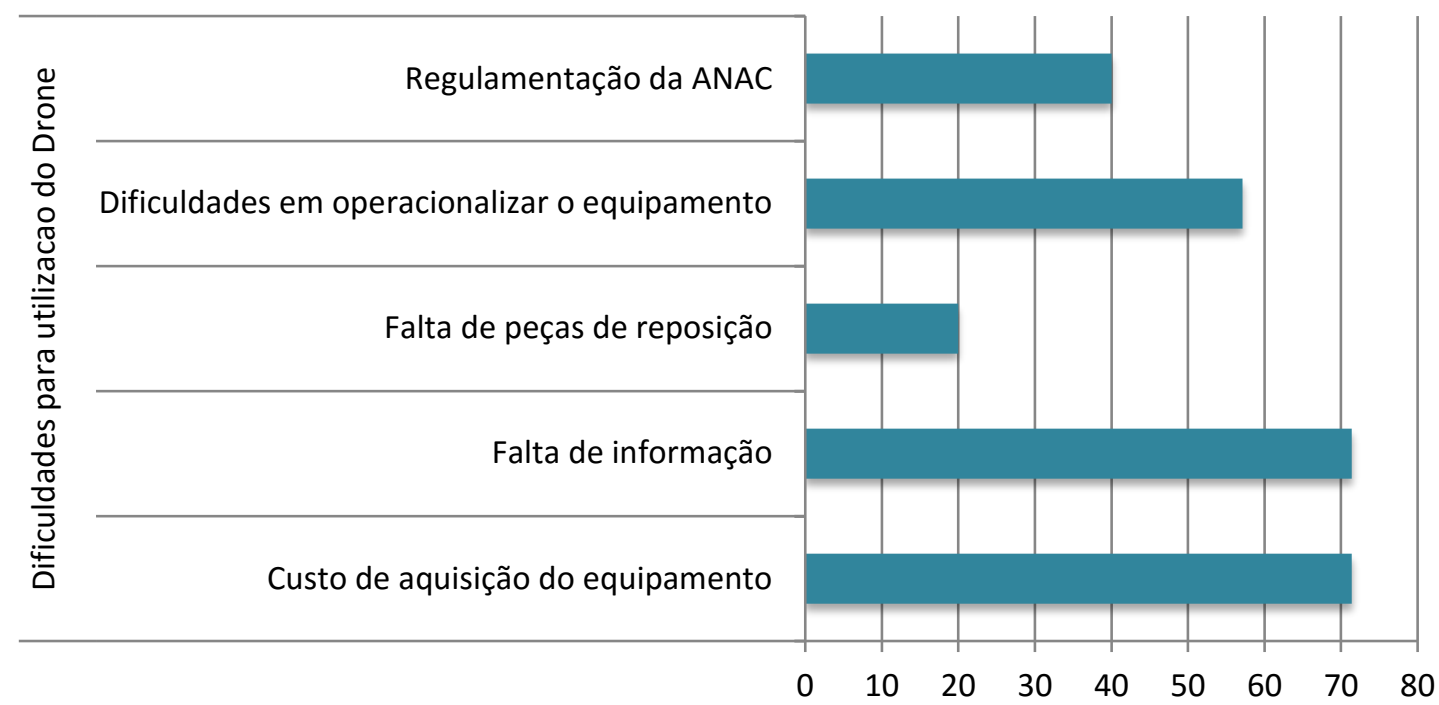

Figura 7. Fatores que levariam a utilização do drone pelos produtores rurais Nota: ${ }^{1}$ Agência Nacional de Aviação Civil [ANAC]

Fonte: Resultado da Pesquisa

Por meio da análise das forças ou fortalezas (Figura 8), os drones apresentam alta precisão na captura de imagens da cultura e uma maior redução no tempo de monitoração de toda a área territorial da lavoura, trazendo maior assertividade e rapidez na análise das informações para a tomada de decisão. Outra força relevante é que existem diversos modelos de VANTs que permitem voar a uma altura menor com sobrevoos mais baixos as lavouras ou alcançarem voos mais altos assim, como percorrerem uma distância maior ou menor de acordo com a finalidade que o agricultor deseja sendo de fácil transporte e manuseio.

Em relação às fraquezas (Figura 8), ainda existem algumas limitações que dificultam a sua maior utilização nos principais estados do Brasil como é o caso da falta de peças de reposição em detrimento a poucas empresas que fornecem este tipo de material no mercado interno. Além disso, não existem estabelecimentos que ofereçam assistência técnica no caso de um eventual dano ou falha do equipamento. Uma outra problemática é a falta de mão-de-obra especializada para a operacionalização do equipamento que são escassas e normas e legislações que permitam o seu uso na 
agricultura por parte da Agência Nacional de Aviação Civil [ANAC]. O custo também pode ser um impeditivo dependendo da característica do drone e da câmera acoplada restringindo o seu uso.

As oportunidades (Figura 8) representam a parte mais promissora do negócio, em virtude do mercado de drones ou VANTs apresentar forte potencial de expansão e com crescimento de 20 a $30 \%$ ao ano, uma vez que a aceitação por parte dos agricultores é bem favorável pelas informações disponibilizadas que permitem uma maior agilidade na tomada de decisão. Além disso, existem poucas empresas no mercado interno vendendo estes equipamentos, o que favorece a entrada de novas companhias, pelo fato de que a maioria dos drones são importados da Europa e EUA o que eleva muito o custo por causa da variação cambial. A falta de instituições de ensino que ofereçam cursos para operacionalizar o equipamento e a ampliação de uso para a pecuária contribuem para o crescimento deste mercado. Por isso, um produto ou uma oferta que consiga oferecer valor e satisfação ao cliente, entre as diferentes ofertas existentes, com maior agregação de valor fará com que se obtenha êxito na atividade (Kotler, 2000).

Todavia existem as ameaças (Figura 8) como em qualquer negócio, como a falta de regulamentação do uso destes equipamentos, que podem permitir que se tenha o uso indevido por parte do usuário trazendo risco a população em geral, como quedas em locais residenciais, uso em áreas impróprias, sobrevoos a baixa altura em áreas de circulação de pessoas, entre outros. Outros fatores que exercem influência neste mercado é a falta de informações e a demora de peças de reposição, que podem levar o agricultor a se decidir pelas ferramentas tradicionais disponíveis na Agricultura de Precisão ao invés deste novo equipamento. Além da falta de uso em outras regiões do país, que dificulta uma maior aceitação entre os produtores rurais.

Assim, este segmento de mercado precisa unir as informações favoráveis (forças e oportunidades), que são os pontos fortes deste produto, para que a possibilidade do negócio possa ser aproveitada e expandida, desenvolvendo ações adequadas de marketing e permitindo ao agricultor maior acesso as informações do uso deste equipamento. Os pontos negativos, como as fraquezas e ameaças, precisam ser levados em consideração para que novas estratégias de mitigação possam ser desenvolvidas e solucionadas, minimizando o risco de ser uma intimidação de mercado, dificultando o seu crescimento (Giuliani, 2008). 


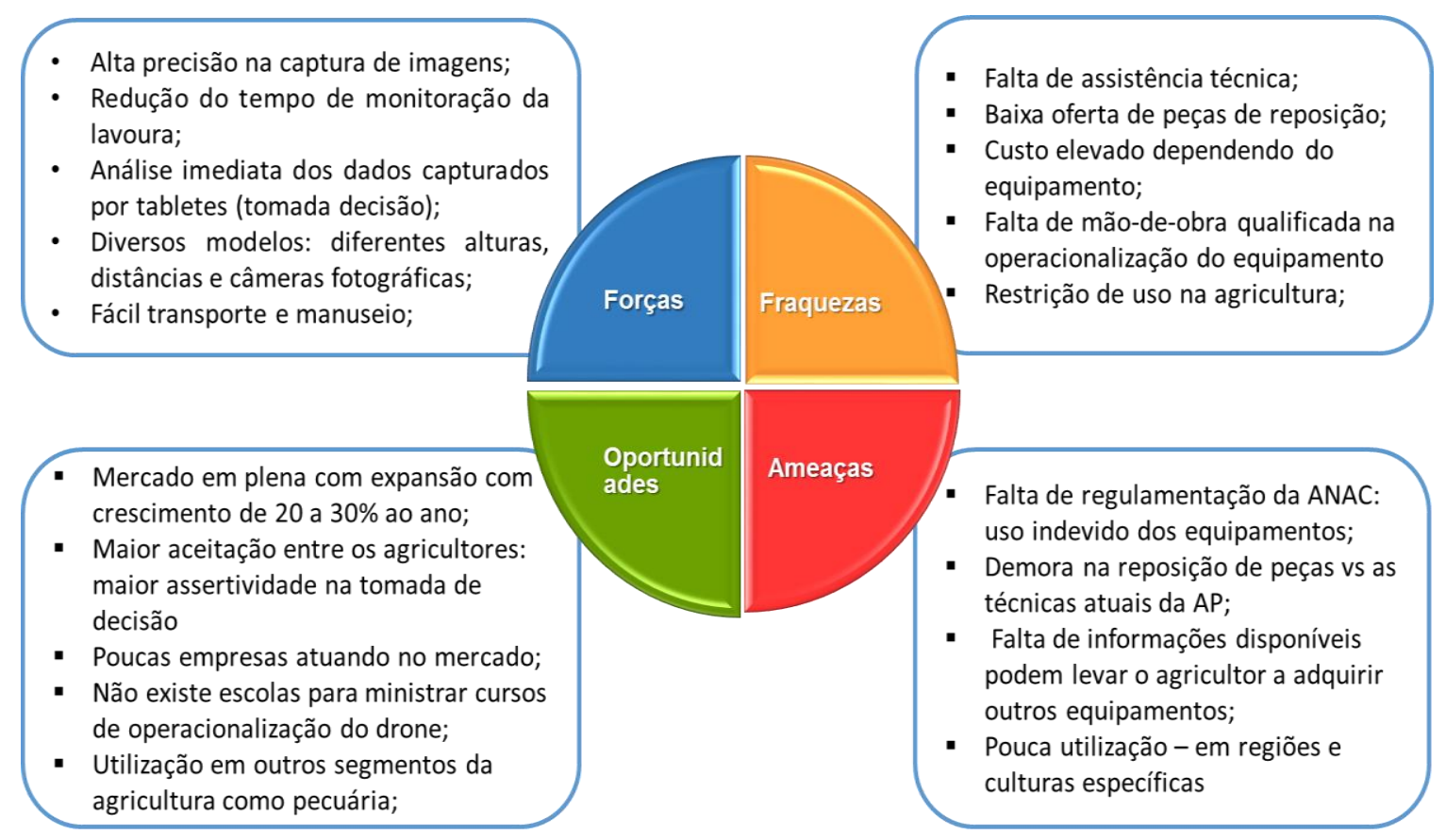

Figura 8. Análise de SWOT em relação ao uso do drone na agricultura de precisão Fonte: Resultado da Pesquisa

\section{Conclusão}

O perfil do profissional mapeado no presente estudo, são fazendeiros que possuem fazendas de 120 ha a 240 ha e que exercem, na maioria das propriedades, 0 cultivo de soja e milho.

Por outro lado, a aceitação do uso dos drones) como uma alternativa às técnicas atuais é alta, o que mostra uma grande oportunidade de aprimorar e expandir este segmento uma vez que garantem maior grau de precisão ao agricultor, do que os satélites habitualmente utilizados para monitoramento da lavoura.

Existem algumas lacunas a serem preenchidas no que diz respeito ao uso dos drones pelos profissionais do agronegócio. A falta de conhecimento dos equipamentos e empresas disponíveis no mercado, a deficiência na operacionalização, o custo de aquisição e a falta de regulamentação da Agência Nacional de Aviação Civil [ANAC], restringem a uma maior utilização do produto nos principais estados do agronegócio brasileiro. 


\section{Referências}

Armstrong, G.; Kotler, P. 2007. Princípios de Marketing. 12ed. Pearson Prentice Hall, São Paulo, São Paulo, Brasil.

Bayer. 2015. Cresce o uso de drones na agricultura. Disponível em: $<$ https://www.redeagroservices.com.br/Noticias/2015/08/Cresce-o-uso-de-drones-naagricultura.aspx>. Acesso em: out. 2015.

Companhia Nacional de Abastecimento [CONAB]. 2015. Safra 2014/15 - Décimo segundo levantamento. Acompanhamento da safra brasileira de grãos 2(12): 1-134.

Giuliani, A.C. 2008. Gestão de Marketing no varejo IV. Ottoni, São Paulo, São Paulo, Brasil.

Instituto Brasileiro de Geografia e Estatística [IBGE].2015. Informações sobre municípios brasileiros. Disponível em: <http://cidades.ibge.gov.br/xtras/home.php.>. Acesso em: out.2015.

Kotler, P.; Armstrong, G. 2000. Administração de Marketing. Pearson Prentice Hall, São Paulo, São Paulo, Brasil.

Lamb Jr, C.W.; Hair Jr, J.F.; McDaniel, C. 2004. Princípios de Marketing. Thomson, São Paulo, São Paulo, Brasil.

Masquietto, C.D.; Giulliani, A.C.; Sacomano, M.N. 2008. Gestão de Marketing no varejo IV. Ottoni, São Paulo, São Paulo, Brasil.

Medeiros, F. A.; Alonço, A. dos S.; Balestra, M. R.; Dias, Vilnei de O.; Landerhal Júnior, M.L 2008. Utilização de um veículo aéreo não tripulado em atividades de imageamento georeferenciado. Ciência Rural (UFSM Impresso) 38: 2375-2378.

Ministério da Agricultura, Pecuária e Abastecimento [MAPA]. 2015. Produto interno bruto da agropecuária deve ser de $\mathrm{R} \$ 1,1$ trilhão. Disponível em:

<http://http://www.agricultura.gov.br/comunicacao/noticias/2014/12/produto-internobruto-da-agropecuaria-deve-ser-de-rs-1-trilhao/>. Acesso em: out. 2015

Molin, J.P. 2001. Agricultura de Precisão - O Gerenciamento da Variabilidade. Piracicaba.

Prates, I. 2015. Rússia inicia produção em série dos satélites de navegação Glonass. Disponível em: <http://mundogeo.com/blog/2015/06/17/russia-inicia-producao-emserie-dos-satelites-de-navegacao-glonass/>. Acesso em: out. 2015.

Organização das Nações Unidas para a Alimentação e a Agricultura [FAO]. 2015. Disponível em:

<http://www.fao.org/fileadmin/templates/wsfs/docs/Issues_papers/HLEF2050_Global_ Agriculture.pdf >. Acesso em: out. 2015.

Secretaria de Relações Internacionais do Ministério da Agricultura, Pecuária e Abastecimento [SRI/MAPA]. 2015. Disponível em:

$<$ http://www.agricultura.gov.br/internacional>. Acesso em: out. 2015. 
Zarco-Tejada, P.J.; Gonzalez-Dugo, V.; Berni, J.A.J. 2012. Fluorescence, temperature and narrow-band índices acquired from a UAV platform for water stress detection using a micro-hyperspectral imager and a thermal camera. Remote Sensing of Environment, v. 117, p. 322-337. Disponível em: http://dx.doi.org/10.1016/j.rse.2011.10.007. Acesso em: out. 2015. 